Vamik D. Volkan ${ }^{1}$

\title{
Psicodinâmica da violência de grandes grupos e da violência de massas
}

\author{
Large-group psychodynamics and massive violence
}

\footnotetext{
1 University of Virginia. 1909 Stillhouse Road, Charlottesville, VA 22901. vdv@virginia.edu
}

\begin{abstract}
Beginning with Freud, psychoanalytic theories concerning large groups have mainly focused on individuals' perceptions of what their large groups psychologically mean to them. This text examines some aspects of large-group psychology in its own right and studies psychodynamics of ethnic, national, religious or ideological groups, the membership of which originates in childhood. I will compare the mourning process in individuals with the mourning process in large groups to illustrate why we need to study largegroup psychology as a subject in itself. As part of this discussion I will also describe signs and symptoms of large-group regression. When there is a threat against a large-group's identity, massive violence may be initiated and this violence in turn, has an obvious impact on public health.
\end{abstract}

Key words Large-group identity, Large-group regression, Wars, Mourning, Chosen traumas
Resumo A partir de Freud, as teorias psicanalistas sobre grandes grupos focalizam, principalmente, as percepções e os significados que, psicologicamente, os indivíduos atribuem a eles. Este texto analisa alguns aspectos sobre a psicologia dos grandes grupos e sua psicodinâmica interna e específica. Toma como referência grupos étnicos, nacionais, religiosos e ideológicos cujo pertencimento dos sujeitos iniciouse na infância. O autor faz uma comparação entre o processo de luto em indivíduos e o processo de luto em grandes grupos para ilustrar por que é necessário investir no conhecimento da psicologia destes últimos como um objeto específico. $O$ autor descreve, ainda, sinais e sintomas de regressão em grandes grupos. Quando há ameaça à identidade coletiva, pode ocorrer um processo de violência de massas que obviamente influencia a saúde pública.

Palavras-chave Identidade de grandes grupos, Regressão de grandes grupos, Guerras, Luto, Traumas selecionados 
Como sou psicanalista, é natural que minha abordagem ao estudo da psicodinâmica e da violência de grandes grupos seja feita primordialmente de uma perspectiva psicanalítica. Em 1932, Albert Einstein escreveu uma carta ao pai da psicanálise, Sigmund Freud, indagando se a nova ciência poderia oferecer soluções capazes de livrar a humanidade da ameaça de guerra. Na resposta a Einstein, Freud ${ }^{1}$ expressou pouca esperança em relação ao fim da guerra e da violência, ou com o papel da psicanálise na mudança do comportamento humano além do nível individual. Muito embora alguns analistas, tais como Jacob Arlow ${ }^{2}$, tenham encontrado indicações de cauteloso otimismo em algumas das obras de Freud, o seu pessimismo geral refletiu-se em muitos de seus seguidores. Creio que isso desempenhou papelchave na limitação das contribuições que a psicanálise propiciou às relações internacionais, em geral, e na obtenção de soluções mais pacíficas para os conflitos entre grupos inimigos, em particular.

A meu ver outro fator de caráter limitativo nas contribuições da psicanálise foi o impacto do Holocausto na prática psicanalítica ${ }^{3}$. Permitam-me explicar: nos esforços iniciais para desenvolver as teorias psicanalíticas, Freud abdicou da idéia de que a sedução sexual das crianças provinha do mundo exterior e, pelo contrário, focalizou os estímulos originários dos próprios desejos e fantasias infantis para a formação da psicopatologia. Como os primeiros psicanalistas seguiram essa tradição, a psicanálise clássica aceitou a falta de ênfase na efetiva sedução oriunda do mundo externo ao considerar o desenvolvimento da psique infantil e generalizou-a, incluindo a falta de ênfase no papel dos casos externos traumáticos. A falta de ênfase abrangeu os casos traumáticos internacionais em seu impacto na saúde mental dos indivíduos por eles afetados. O Holocausto é o exemplo por excelência. Por muito tempo, os estudos psicológicos do Holocausto eram por demais dolorosos para serem realizados, evitando-se todo o tópico de seu impacto psicológico nos que foram diretamente afetados e na psique humana em geral.

Apesar de alguns estudos desse tópico, em geral uma "negação" da condição psicológica dos sobreviventes do Holocausto estranhamente persistiu durante décadas após a Segunda Guerra Mundial uma defesa que se estendeu, de maneira espantosa, até Israel. Em 2 de novembro de 1995, uma estação israelense de televisão informou em resenha que, mesmo o Estado judaico, negligenciara por muito tempo o trauma sofrido pelos sobreviventes do Holocausto. Depois de sua chegada, nos anos 40, os sobreviventes haviam sido logo tratados de de- pressão e de outros transtornos mentais em hospitais psiquiátricos. Entretanto, por incrível que pareça, muitas das fichas oficiais desses pacientes sequer mencionam o fato de terem sido vítimas do Holocausto.

A descrição de Harold Blum ${ }^{4}$ sobre um paciente judeu que o procurou para reanálise ilustra a extensão da possível prevalência de resistências mútuas quando tanto o analista quanto o analisando pertencem ao mesmo grande grupo submetido a traumatismo intenso, causado por acontecimento histórico externo. O primeiro analista do paciente de Blum, também judeu, deixou de "ouvir" no material do analisando o trauma comum, sofrido por seu grande grupo, que fora infligido pelas mãos dos nazistas. Em conseqüência, o silêncio e a negação sancionados por ambos permearam toda a experiência analítica, deixando resíduos não analisados das questões relacionadas ao Holocausto nos sintomas do analisando.

Podemos imaginar quantos analistas judeus após a Segunda Guerra Mundial eram como o ex-analista do paciente de Blum e quantos deles, sem se darem conta, influenciaram a aplicação do tratamento psicanalítico com tendência a ignorar a realidade externa relacionada ao Holocausto. Sugiro que alguns deles, muito influentes no campo da psicanálise, tanto nos EUA quanto alhures, exageraram a propensão em favor da posição teórica denominada "análise clássica", que enfocava apenas as fantasias e os desejos internos do analisando. Hoje sabemos que, depois da Segunda Guerra Mundial, também na Alemanha houve resistência (inconsciente) por parte dos analistas, tanto alemães quanto judeus alemães, no sentido de explorar o entrelaçamento dos conflitos internos e externos e a influência das questões relacionadas ao Holocausto na psique dos analisandos ${ }^{5-9}$.

A partir de Freud, muitos autores que não são, eles próprios, psicanalistas praticantes valeram-se da psicanálise, na tentativa de compreender a psicologia das questões mundiais e dos grandes grupos em geral. Com freqüência, eles se referem às obras de Freud ${ }^{10-13}$, tais como Totem e Tabu, Psicologia de grupo e Análise do ego, O futuro de uma ilusão, Civilização e seus descontentamentos, e à sua correspondência com Einstein já mencionada. $\mathrm{O}$ principal problema dessa abordagem, conforme foi observado por Ivan Hendrick ${ }^{14}$ há muito tempo, é que, devido a ela, a psicanálise é malusada pelos intelectuais, que alegam sua validade como se fora uma filosofia, um sistema ético, um conjunto de teorias; essa discussão [...] parece extrínseca e improdutiva para o próprio analista, cujas 
convicções básicas se originam no que lhe é dito pelos pacientes. Na abordagem desses autores, em geral, duas importantes considerações passam despercebidas. Em primeiro lugar, as teorias psicanalíticas que sistematizam novas descobertas no campo tiveram enorme desenvolvimento nas décadas que se seguiram à obra pioneira de Freud. Por segurança, alguns autores que não estão praticando a psicanálise agora se referem a novos teóricos da psicanálise, como Jacques Lacan, ao escreverem sobre a psicologia de grandes grupos. Normalmente, porém, esses autores também utilizam as novas teorias psicanalíticas como se fossem um conjunto de considerações filosóficas.

Em segundo lugar, as observações propiciadas pela prática psicanalítica têm muito mais a oferecer ao estudo de questões mundiais, identidade étnica, interações dos seguidores de líderes políticos, erupção da violência em massa e sua influência na saúde pública. De meu ponto de vista, o trabalho com crianças na terapia psicanalítica, ou a análise de adultos fronteiriços ou narcisistas, tem caráter mais informativo sobre a psicologia de grandes grupos do que o estudo da metapsicologia ou das teorias psicanalíticas da mente. Com freqüência, as relações internacionais são dominadas pela utilização de mecanismos primitivos de defesa comuns, tais como introjeção, projeção, clivagem e negação. O trabalho clínico com crianças, pacientes fronteiriços e narcisistas nos ensina bastante sobre esses mecanismos.

Nesse meio tempo, os psicanalistas praticantes, com algumas exceções, basicamente tenderam a tratar os pacientes sem muito interesse nem atenção no tocante às questões políticas ou diplomáticas e aos enormes problemas de saúde pública encontrados nas sociedades traumatizadas em massa. Ao escreverem sobre essas questões, eles aplicam teorias da psicologia individual aos processos de grandes grupos, sem levar em consideração que tais processos, uma vez iniciados, tomam seus próprios rumos específicos e surgem como novos movimentos políticos, sociais ou ideológicos. Recentemente, todavia, em especial após o dia 11 de setembro de 2001, os psicanalistas praticantes vêm demonstrando mais interesse na psicologia de grandes grupos.

Minhas descobertas na psicologia de grandes grupos provêm do efetivo trabalho de campo em vários pontos conflituosos no mundo. Em 1977, o então presidente do Egito, Anwar Sadat, causou estupefação no mundo político ao visitar Israel. Dirigindo-se ao parlamento israelense, ele falou sobre o muro psicológico entre árabes e israelenses e declarou que as barreiras psicológicas constituem 70 por cento de todos os problemas entre os dois povos. Com as bênçãos dos governos egípcio, israelense e norte-americano, o Comitê de Psiquiatria e Relações Exteriores da Associação Psiquiátrica Americana (APA), em seguimento às declarações de Sadat, reuniu israelenses, egípcios e depois palestinos influentes para uma série de negociações inoficiais realizadas de 1979 a 1986. Minha participação nesse comitê deu início a meu estudo sobre psicologia de grandes grupos, relações entre adversários, e interações entre líderes políticos e seus seguidores. Comecei, então, a contemplar estratégias para abrandar a agressão entre grupos inimigos.

Esse estudo de seis anos de duração sobre o conflito árabe-israelense visto sob óptica psicológica também me deu a oportunidade de examinar a psicologia intrínseca de grandes grupos e sociedades. Mais tarde observei outros representantes de "inimigos" - como russos e estonianos, georgianos e servos e croatas da Ossétia do Sul ou turcos e gregos - em numerosas séries de negociações inoficiais que levaram anos. Também entrevistei pessoas traumatizadas em campos de refugiados, onde o "sentimento coletivo" se torna palpável. Além do mais, convivi certo tempo com líderes políticos, tais como o expresidente dos EUA Jimmy Carter; o ex-líder soviético Mikhail Gorbachev; o falecido Yasser Arafat; o atual presidente da Estônia, Arnold Rüütel; e o do Norte do Chipre, Rauf Denktas. Tive oportunidade de observar aspectos da psicologia dos seguidores de líderes por meio dos processos do pensamento verbalizado e dos atos desses líderes. Por fim, pude definir o conceito de "identidade de grandes grupos": um sentimento de afinidade partilhado por milhares ou milhões de pessoas. Esse sentimento de afinidade explica o que as pessoas querem dizer quando afirmam, "somos finlandeses", "somos árabes", "somos judeus" ou "somos comunistas"15-19.

\section{Identidade de grandes grupos}

Devido ao interesse clínico, os psicanalistas se concentraram mais em pequenos grupos e na psicodinâmica envolvida quando 7 a 15 indivíduos se congregam em uma série de reuniões. A obra de Wilfred Bion ${ }^{20}$ está entre as mais conhecidas desses estudos. Um "pequeno grupo" com líder definido, tarefa estruturada e noção de tempo funciona como um "grupo de trabalho" e desempenha sua tarefa adaptada à realidade. Bion descreve a maneira pela qual, quando a segurança 
do grupo sofre ameaça ou quando não lhe é dada tarefa realista e estruturada, ele passa a funcionar segundo determinados "pressupostos básicos" muito familiares aos psicanalistas.

$\mathrm{Na}$ literatura psicanalítica o termo "grandes grupos", em geral, se refere a conjuntos de 30 a 150 membros que se reúnem para tratar de determinada questão. Quando a tarefa dada ao "grande grupo" é desestruturada e vaga, ele regride. Nesse momento, os observadores notam crescente ansiedade, caos e pânico entre os membros ${ }^{21-24}$. Para escaparem da atmosfera de pânico que os evolve, os "grandes grupos" em estado de regressão exibem características narcísicas ou paranóicas e se reorganizam partilhando e utilizando mecanismos mentais primitivos.

Otto Kernberg também se refere a grupos compostos de 30 a 150 indivíduos como "grandes grupos." Ele usa o termo "multidões" para se referir aos espectadores de grandes acontecimentos desportivos ou espetáculos teatrais de vulto. Também menciona desorganização em multidões após desastres naturais e, então, refere-se a "movimentos de massa" e "processos sociais e culturais". Ele ilustra basicamente o surgimento da agressão em "pequenos grupos", "multidões" e "sociedades" quando a regressão e a desorganização se instalam.

Neste texto, refiro-me a dezenas, centenas, milhares ou milhões de indivíduos - a maioria dos quais jamais se encontrará na vida - que pertencem a um grande grupo desde a infância. Utilizo o termo identidade de grandes grupos (isto é, identidade étnica) para aludir a um permanente sentimento compartilhado de afinidade.

A psicodinâmica de grandes grupos étnicos, nacionais, religiosos ou ideológicos é diferente da psicodinâmica de "pequenos grupos", "grandes grupos" (compostos de 30 ou 150 indivíduos), ou "multidões". Por exemplo, uma "multidão" em um estádio de futebol torna-se um grupo, e assim permanece, pouco antes do evento desportivo, durante sua realização e talvez logo após o seu término. Por outro lado, consideremos um grande grupo étnico ou religioso, como gregos ou católicos. O pertencimento nesses grandes grupos começa na infância. Em outros trabalhos, ilustro como o cerne da identidade pessoal de cada membro é entrançado com a identidade de seu grande grupo16, 19.

Quando penso a respeito da teoria freudiana clássica de grandes grupos, visualizo pessoas reunidas em torno de um gigantesco mastro repleto de flores, nos festejos da primavera, que representa o líder do grupo. Os indivíduos do grande grupo dançam em volta do mastro/líder, identificando-se entre si e idealizando o líder. Ampliei a metáfora do mastro de flores imaginando uma lona estendida sobre as pessoas, a partir do mastro, para formar uma imensa tenda. A lona representa a identidade dos grandes grupos. Cheguei à conclusão de que a psicodinâmica essencial dos grandes grupos concentra-se na manutenção da integridade de sua identidade, e as interações dos seguidores dos líderes constituem apenas um elemento desse esforço.

Imaginem milhares ou milhões de pessoas vivendo sob essa imensa tenda. Elas podem formar subgrupos - seja de pobres ou ricos, mulheres ou homens, integrantes de determinados clãs ou organizações profissionais -, mas todas elas se encontram sob a mesma imensa tenda. O mastro da tenda é a liderança política. Do ponto de vista da psicologia individual, o mastro pode representar o pai edipiano; do ponto de vista da psicologia de grandes grupos, a tarefa do mastro é conservar a lona ereta (manter e proteger a identidade dos grandes grupos). Todos sob a lona da tenda trajam uma veste individual (identidade pessoal); todavia, todos sob a tenda também partilham a lona da tenda como segunda veste. Em outros trabalhos, identifiquei sete ameaças que, ao serem interlaçadas, produzem um tecido - a lona da tenda dos grandes grupos - que varia das identificações comuns aos "traumas selecionados"17, 19, termo que explicarei mais adiante.

$\mathrm{Na}$ vida rotineira não ficamos muito atentos à nossa segunda veste comum, como em geral não estamos conscientes de nossa permanente respiração. Se pegarmos pneumonia ou se estivermos dentro de um edifício em chamas, logo observaremos cada movimento respiratório. Da mesma maneira, se a lona de nossa imensa tenda balançar ou partes dela se romperem, ficaremos obcecados com nossa segunda veste, e nossa identidade individual se torna secundária. Antes de seguir adiante, devo explicar que me refiro a processos de grandes grupos em geral, desconsiderando determinadas pessoas, tais como os dissidentes. A preocupação passa a ser com a identidade do grande grupo, e fazemos de tudo para estabilizá-la, repará-la, mantê-la e protegê-la; e, nesse intento, estamos dispostos a tolerar sadismo ou masoquismo extremos, se julgarmos que nossa ação irá ajudar a manter e proteger a identidade do grande grupo. No final, esse comportamento terá reflexo inevitável nas questões de saúde pública.

\section{Psicodinâmica de grandes grupos}

Como os grandes grupos são constituídos de indivíduos, é lógico que os processos de grandes 
grupos refletem a psicologia individual. Todavia, um grande grupo não é um organismo vivo com um único cérebro; daí, quando um processo de grande grupo se inicia dentro da sociedade, ele ganha vida própria. Para ilustrar o fato, vou comparar o processo de luto de um indivíduo com o de um grande grupo.

Os psicanalistas, psiquiatras e outros profissionais da saúde mental sabem bastante sobre o processo de luto individual. O luto é uma reação psicobiológica humana obrigatória a uma perda significativa. Quando um ente querido morre, o enlutado tem de passar por fases previsíveis e definíveis até o processo de luto chegar a um fim prático ${ }^{25,26}$. O psicanalista finlandês Veikko Tähkä27, juntamente com outros que retrocedem ao próprio Sigmund Freud ${ }^{29}$, muito contribuiu para a nossa compreensão do processo de luto individual, durante o qual o enlutado faz uma revisão interna das experiências com o ente perdido e, pouco a pouco, deixa que ele psicologicamente seja "sepultado". Se tudo transcorre de forma rotineira, o enlutado também identifica aspectos e funções do morto quando ainda em vida, mantendo-o "vivo" dentro de sua psique. Esse processo leva alguns anos. Às vezes, o processo de luto individual pode ser "infectado" por várias causas, sendo possível prever o que acontece após essas "infecções".

Os grandes grupos também guardam luto. Por não constituírem um único organismo vivo, a psicodinâmica de seu luto pela perda de entes queridos, terras e prestígio, após uma guerra ou situações similares de conflito, vai se manifestar como um processo social. Por exemplo, depois de grave perda e trauma comuns, infligido pelas mãos de inimigos, uma ideologia política de irredentismo - noção partilhada do direito de recuperar o que foi perdido - pode surgir, refletindo uma complicação no luto de grandes grupos e uma tentativa tanto de negar as perdas quanto de recuperá-las. O que os gregos denominam Megali Idea (Grande Idéia) representa esse tipo de ideologia política. Essas ideologias políticas podem durar séculos e desaparecer e reaparecer quando as circunstâncias históricas mudam ${ }^{29}$.

A última vez em que testemunhamos com clareza o ressurgimento de uma ideologia política desse direito ocorreu após o colapso da Iugoslávia. Quando a imensa tenda iugoslava desapareceu, servos, croatas, bósnios e outros se preocuparam em se estabelecer sob suas respectivas tendas menores. Quando um grande grupo se indaga "quem somos nós agora?", ele está preocupado em reparar, proteger e manter a lona de sua tenda. Para manter a identidade, o grande grupo tenta realçar símbolos específicos urdidos na textura da lona de sua tenda. Quando as marcas da identidade étnica, nacionalista, religiosa ou ideológica são realçadas, isso reassegura à sociedade a existência da identidade de seu grande grupo. Denominei uma dessas marcas importantes de trauma selecionado.

Trauma selecionado é a representação mental partilhada de um acontecimento na história de um grande grupo no qual houve perda catastrófica, humilhação e sentimento de desamparo nas mãos de inimigos. Quando os membros do grupo vitimado não podem prantear as perdas e revertem a humilhação e o desamparo, eles passam para os descendentes as imagens de sua individualidade lesionada e as tarefas psicológicas que precisam ser concluídas. Esse processo é conhecido como "transmissão transgeracional do trauma"9. Todas as imagens e tarefas contêm referências ao mesmo acontecimento histórico e, no decorrer de décadas, a representação mental do acontecimento une todos os indivíduos do grande grupo. Portanto, a representação mental do acontecimento surge como uma marca importante da identidade do grande grupo. O trauma selecionado reflete a "infecção" do processo de luto do grande grupo, e sua reativação serve para unir seus membros. A reativação pode ser usada pela liderança política para promover novos movimentos sociais de massa, alguns deles fatais e malignos.

Os líderes políticos podem deflagrar a reativação dos traumas selecionados com intuito de nutrir ideologias de direitos. A história de como Slobodan Miloševic permitiu e apoiou o reaparecimento do trauma selecionado sérvio - a representação mental da Batalha do Kosovo de 28 de junho de 1389 - está bem documentada ${ }^{16}$. Segundo o mito desenvolvido entre os sérvios, cerca de 70 anos após a Batalha do Kosovo, o acontecimento e os personagens sérvios da batalha - especialmente o líder sérvio, o Príncipe Lazar, que foi morto em combate - misturaram-se com elementos e personagens do cristianismo. No transcorrer de décadas, o Príncipe Lazar passou a ser associado a Jesus Cristo, e ícones com a representação de Lazar de fato decoraram muitas igrejas sérvias durante os seis séculos que se seguiram à batalha. Mesmo durante o regime comunista, quando o governo desencorajava o culto de heróis, os sérvios podiam beber (introjetar) um vinho tinto popular chamado Príncipe Lazar.

Em 1989, próximo ao sexcentésimo aniversário da Batalha do Kosovo, com a autorização e o encorajamento de Miloševic, os restos mortais de Lazar, que haviam sido sepultados no norte de Belgrado há 600 anos, foram depositados em um caixão e 
levados ao longo daquele ano a quase toda vila e cidade sérvia, onde eram recebidos por enormes multidões de pranteadores vestidos de preto. Repetidamente durante o longo trajeto, os restos mortais de Lazar eram enterrados e reencarnados de maneira simbólica, até o sepultamento definitivo no solo original da Batalha do Kosovo, no dia 28 de junho daquele ano. $\mathrm{Na}$ data em que se comemoravam os 600 anos da referida batalha, um helicóptero transportou Miloševic ao local da cerimônia fúnebre, onde fora erigido um imenso monumento de pedra vermelha simbolizando sangue. Na mitologia, o Príncipe Lazar trocara o Reino da Terra pelo Reino dos Céus. Propositadamente, Miloševic saltou do helicóptero representando o Príncipe Lazar, que descia à Terra para encontrar um novo Reino - a Grande Sérvia.

Assim, Miloševic e seus asseclas, ativando as representações mentais de Lazar e da Batalha do Kosovo, juntamente com as emoções aguçadas que elas geravam, foram capazes de criar uma "condensação temporal" de um ano de duração: as percepções, os sentimentos e as expectativas referentes a um herói e acontecimento do passado condensaram-se nas percepções, nos sentimentos e nas expectativas sobre um "inimigo" atual, ampliando, assim, a sua ameaça. Miloševic e seus asseclas primeiro encorajaram uma noção comum de vitimização, seguida por uma noção comum de direito à vingança. Isso levou aos atos de genocídio na Europa no final do século 20. No início de junho de 2005, novos vídeos revelando assassinatos violentos em nome da identidade de um grande grupo chocaram os cidadãos sérvios - bem como o restante do mundo.

Imaginemos um assassino em série como Jack, o Estripador, que matava suas vítimas por estrangulamento com um lenço vermelho. Imaginemos também esse assassino em série sendo apanhado, julgado e preso. O que acontece com a arma do crime, o lenço vermelho? Fica dentro de uma caixa empoeirada, no porão do edifício da delegacia de polícia ou do fórum, como prova usada durante o processo judicial. Em síntese, no futuro ninguém mais usará esse lenço como "instrumento" para matar alguém.

Voltemos a Miloševic. No momento atual ele está sendo julgado porque as Nações Unidas o consideram responsável por assassinato em massa, entre outros delitos. Qual foi o "lenço vermelho" de Miloševic e o que aconteceu com ele? Como descrito acima, um dos "instrumentos" principais de Miloševic para incitar a violência extrema foi reativar (com a ajuda de alguns acadêmicos e integrantes da Igreja Sérvia) símbolos comuns da identidade do grande grupo sérvio: as representações mentais de perda e humilhação, a Batalha do Kosovo, e o líder sérvio, Príncipe Lazar, morto em combate.

Agora imaginemos que Miloševic seja considerado culpado e preso, mas seu "lenço vermelho" não é guardado no porão. Como esse "lenço vermelho" pertence a um grande grupo e não a um indivíduo, é possível que venha a ser usado de novo no futuro. Sabemos disso porque Miloševic não é o primeiro a inflamar as representações mentais da Batalha do Kosovo e do Príncipe Lazar. Em 28 de junho de 1914, durante um dos aniversários da Batalha do Kosovo, um sérvio chamado Gavrilo Prencip assassinou o arquiduque Francisco Ferdinando do Império Austro-Húngaro (a Áustria-Hungria substituíra o Império Otomano como "opressor" dos sérvios) e sua mulher grávida, em Sarajevo, deflagrando com isso a Primeira Guerra Mundial.

Os sistemas político e judicial não dispõem de métodos efetivos para lidar com um "instrumento" capaz de ser usado para a destruição em massa, quando ele pertence a um grande grupo ao invés de a apenas um homem ou mulher. Isso é mais bem compreendido pela aplicação de insights psicológicos que realçam os processos intrínsecos de grandes grupos, em vez de conceitualizações lógicas da política internacional baseada em fatores pragmáticos e materiais. Quem vai examinar os "lenços vermelhos" pertencentes a grandes grupos? Assevero que os psicanalistas e outros estudiosos da natureza humana encontram-se mais bem equipados para a tarefa, caso estejam dispostos a se aventurar além de seus consultórios, realizando trabalho de campo e colaborando com pesquisadores acadêmicos e profissionais praticantes de outras disciplinas no esforço de entender as questões humanas coletivas, tais como política, diplomacia, guerras, terrorismo e o reflexo desses fatores no âmbito da saúde pública.

\section{Regressão de grandes grupos}

Quando a identidade de um grande grupo fica ameaçada - o que pode ocorrer diante de inúmeros fatores como, por exemplo, por inimigos do grupo - o grande grupo étnico, nacional, religioso ou ideológico sofre regressão. Conquanto tenha encontrado 20 sinais e sintomas desse tipo de regressão ${ }^{17}$, preciso tomar emprestado o termo "regressão" da psicologia individual devido à inexistência de uma palavra que signifique apenas a regressão de um grande grupo. Ao regredir, o grande 
grupo se envolve em determinado processo social que serve para manter, proteger e reparar a sua identidade. Já que os grandes grupos, como aqui descritos, possuem suas próprias características específicas que são criadas sobre suas representações mentais da história e do mito, partilhadas e contínuas durante séculos, o exame dos sinais e sintomas da regressão também devem incluir uma psicodinâmica partilhada que seja específica de cada grupo. Assim sendo, precisamos ir além da descrição geral do surgimento da agressão em grandes grupos, quando eles regridem, e de seus sentimentos paranóicos ou narcísicos comuns, e consultar as manifestações efetivas da regressão dentro de cada grande grupo específico.

Alguns importantes sinais da regressão de grandes grupos, tais como cerrar fileiras em torno do líder - como aconteceu nos EUA logo após os ataques terroristas de 11 de setembro de 2001 são conhecidos desde a época de Freud. Quando escreveu sobre o fenômeno, Freud ${ }^{11}$ não disse que se referia à regressão de grupos, e foi Robert Waelder ${ }^{30}$ quem chamou a atenção para o fato de a descrição de Freud ser realmente sobre esse tópico. Às vezes, os membros de um grande grupo continuam a cerrar fileiras em torno do líder durante décadas e permanecem em estado de "regressão" a fim de modificar as características existentes da identidade de seu grande grupo. Nessa situação, o que observamos é similar à regressão individual a serviço da progressão e criatividade. Depois do colapso do Império Otomano e do estabelecimento da Turquia moderna em 1923, sob a liderança de Kemal Atatürk, o povo turco (em geral) manteve sua posição em torno de Atatürk até sua morte em $1938^{29}$. Esse foi o principal fator de suporte para a revolução cultural da Turquia moderna e para a modificação das características da identidade do grande grupo turco.

Com freqüência, no entanto, a regressão de um grande grupo não traz resultados positivos. Por exemplo, em determinados regimes totalitários, as pessoas cerram fileiras em torno do líder para se sentir seguras em termos pessoais, em vez de serem punidas pelas autoridades por desobedecerem as "regras" do regime. Sem consciência disso, elas internalizam o que Michael Sebek ${ }^{31}$ denominou de "objetos totalitários," e seguem o líder de maneira cega abrindo mão de muitos aspectos de sua individualidade.

Quando um grande grupo encontra-se em estado de regressão, a personalidade e o mundo interno do líder político assume grande importância no que tange à manipulação (o "bom" ou o "mal") do que já existe na psicologia do grande grupo. Desse modo, a organização da personalidade de Miloševic, que descrevo em outro trabalho ${ }^{16}$, constituiu fator crucial no que aconteceu na antiga Iugoslávia, e demonstra como líderes políticos à semelhança de Miloševic irão trazer à tona os "lenços vermelhos" dos grandes grupos e usá-los como instrumentos de agressão em massa.

Dois tipos de clivagem também constituem sinais de regressão de grandes grupos. Em primeiro lugar, a clivagem entre "nós" e "eles" (o inimigo fora do grande grupo em estado de regressão) torna-se pronunciada e o "outro" passa a ser alvo da desumanização. Em segundo lugar, após cerrar fileiras em torno do líder, pode ocorrer uma clivagem grave dentro da própria sociedade. Ela acontece, em especial, quando o líder não é capaz de diferenciar onde termina o perigo real e começa o perigo fantasiado e, pelo contrário, faz com que o grupo se pareça com o inimigo em determinadas áreas, como no cerceamento dos direitos individuais. Sem essa diferenciação, o grupo fica incapaz de manter a esperança e não consegue dominar a agressão comum. Poucos anos após o ataque de 11 de setembro, observamos essa clivagem nos EUA. Há vários motivos para tanto, mas creio que isso também reflete o estado de regressão dos Estados Unidos após a tragédia em massa, bem como a falha na liderança norteamericana de diferenciar os perigos "reais" dos "fantasiados" e sua incapacidade de ajudar a abrandar a ansiedade comum da população.

A regressão dentro de um grande grupo estimula a população a partilhar mecanismos mentais ao lidar com o mundo externo. Refiro-me a introjeções (como a população "engolindo" a propaganda política, sem fazer esforço para avaliar sua validade) e projeções em massa, como ocorreu sob o regime totalitário de Enver Hoxha, quando os albaneses construíram 7.500 bunkers por todo o país como medida preventiva a um ataque inimigo que jamais se deu. Construir os bunkers, que não resistiriam às armas modernas, também era reflexo do pensamento mágico, outra característica das sociedades em estado de regressão. Vemos vários tipos de pensamento mágico, como a expansão do fundamentalismo religioso e o aumento da crença no milenarismo nos EUA, que exerce forte influência nos movimentos políticos e sociais daquele país no momento atual.

Em uma sociedade em estado de regressão, as fronteiras políticas, legais ou tradicionais passam a simbolizar a lona da tenda dos grandes grupos. Em outras palavras, as fronteiras se tornam alta- 
mente psicologizadas, e o povo, os líderes e as organizações oficiais começam a se preocupar com sua proteção. Como há de fato um perigo real "lá fora", é obvio que as fronteiras precisam ser protegidas e, por isso, é difícil estudar os aspectos psicológicos dessa preocupação. Nos EUA, as pessoas agora estão sujeitas à influência de uma psicologia de fronteira quase todos os dias, mas, devido à ampliação do perigo real (e fantasiado) pela propaganda política, elas podem não estar cientes da influência dessa psicologia de fronteira na rotina de suas vidas. Nos aeroportos, por exemplo, elas negam a violação da autonomia individual nos pontos de verificação de segurança devido à possibilidade do perigo real. Com isso, elas se sujeitam à psicologia do grande grupo, e a psicologia individual, que normalmente faria com que se rebelassem contra a intrusão de fora, é colocada em segundo plano.

Quando a lona da tenda de um grande grupo é atacada e rasgada, as "pequenas diferenças" entre os grupos inimigos tornam-se questões de vulto, já que passam a ser vivenciadas como "fronteiras" imutáveis que separam a identidade do grande grupo da identidade do inimigo. As pessoas, então, ficam preocupadas não só com as diferenças de vulto entre seu grupo e o grupo inimigo, mas também com as pequenas diferenças existentes.

Quando um grande grupo sofre regressão, os valores tradicionais da família podem ser substituídos por ideologia, como aconteceu na Alemanha nazista. Em alguns grandes grupos no estado de regressão, o papel da mulher se restringe a proporcionar prazer a homem (sexo), prover alimento (leite simbólico para a sociedade sob estresse) e gerar filhos para a sobrevivência da identidade do grande grupo. Determinados processos sociais começam a lembrar a todos sobre a permanente existência da lona (identidade do grandes grupos). Os costumes culturais são como desenhos na lona que ilustram a singularidade da identidade daquele grande grupo em particular. O grupo deseja "repintar" os desenhos na lona para aliviar a ansiedade comum e para mostrar que sua identidade ainda sobrevive. Contudo, na realidade, ele se sente desamparado, raivoso, humilhado, submetido a um complexo processo de luto. Portanto, quando são "repintados", os desenhos não se assemelham exatamente aos originais; parecem então malfeitos e, em alguns aspectos, exagerados. Isso pode facilmente levar a problemas de saúde pública como, por exemplo, no que hoje é a República da Geórgia. Após o colapso da União Soviética, lutas sangrentas foram travadas entre georgianos étnicos e ossetas étnicos que viviam dentro das mesmas fronteiras políticas/legais e, de fato, os ossetas declararam seu próprio "Estado independente". Os aspectos da regressão de grandes grupos ainda remanesce na Ossétia do Sul, bem como na Geórgia. Havia um ritual cultural jocoso com respeito às noivas, no qual a garota era simbolicamente raptada para casar. Os costumes culturais do rapto na Ossétia do Sul transformaram-se hoje em terríveis problemas sociais na forma de raptos reais e estupros de mulheres jovens.

Precisamos estudar a situação de cada grande grupo sob vários ângulos para descobrir os elementos específicos de seus processos, a fim de compreender os significados subjacentes e, então, começar a planejar estratégias políticas baseadas em informações psicológicas para induzir a progressão dentro de um, dois ou mais grandes grupos em conflito. A sessão seguinte consiste em um resumo do método chamado "modelo de árvore", que oferece tais estratégias e a sua aplicação.

\section{O "modelo de árvore" e a progressão de grandes grupos}

O "modelo de árvore", que ajudei a desenvolver ao longo de cerca de 30 anos de efetivo envolvimento com uma equipe interdisciplinar de relações internacionais, utiliza-se da imagem do crescimento gradativo e da ramificação de uma árvore para ilustrar seus métodos. Essa metodologia tem três fases ou componentes básicos: 1) o diagnóstico psicopolítico da situação; 2) os diálogos psicopolíticos entre os membros dos grupos oponentes; e 3) as medidas e instituições de colaboração que surgem do processo de diálogo. A primeira fase inclui entrevistas baseadas em informações psicanalíticas profundas, realizadas com amplo leque de pessoas que representem os grupos envolvidos, através das quais tenha início uma compreensão dos principais aspectos, inclusive os inconscientes, que envolvem a situação a ser tratada. Os diálogos psicopolíticos entre representantes influentes de grandes grupos oponentes são realizados sob a orientação de uma equipe de facilitadores e têm lugar em uma série de reuniões, por diversos dias, ao longo de vários anos. À medida que os diálogos progridem, as resistências contra mudar os meios "patológicos" dos grandes grupos para protegerem sua identidade são trazidos à tona e articulados, de modo que as ameaças fantasiadas às suas identidades podem ser interpretadas, tendo lugar uma comunicação realista. Para os insights recém-adquiridos terem impacto nas diretrizes políticas e sociais, bem como na população como um todo, a fase final re- 
quer o desenvolvimento cooperativo de medidas, programas e instituições concretas. Essa metodologia permite que diversas disciplinas, inclusive a psicanálise, a história e a diplomacia, colaborem na articulação e no trabalho, por meio dos aspectos históricos e psicológicos subjacentes às tensões existentes. O que é aprendido é depois operacionalizado para que se alcance coexistência mais pacífica entre grandes grupos e as ameaças (especialmente as fantasiadas) às suas identidades provenientes do "outro" se abrandem. Isso leva à progressão dentro do grande grupo ${ }^{19}$.

Nos sinais de progressão dos grandes grupos está incluída a preservação da individualidade, ao tempo em que se estabilizam os subgrupos familiares, profissionais e do clã, e se alcança uma sociedade na qual as organizações individuais e profissionais estabelecem a capacidade de fazer acordos sem danos à integridade ${ }^{32}$ e de questionar o que é "moral." Quando o grande grupo não se encontra em estado de regressão, dá-se maior ênfase à liberdade de expressão, acaba-se com a desvalorização de mulheres e crianças e presenciam-se instituições civis justas e em funcionamento, especialmente um sistema judiciário legítimo e hospitais mentais com cuidadosa assistên$\mathrm{cia}^{33}$. Quando um grande grupo não se encontra em estado de regressão, seus membros (em geral) podem se questionar sobre a "realidade psíquica" do inimigo. Entender os motivos do comportamento pernicioso do "outro" não significa perdoar ou esquecer os erros do passado. Significa desempenhar a difícil tarefa de "humanizar" até mesmo os perpetradores mais destrutivos. Os atos terríveis em grande escala não são praticados por "demônios", mas por seres humanos sob influência específica da psicologia de grandes grupos. Espero fique claro que não focalizo aqui indivíduos que, devido à sua própria psicologia individual, geram caos e tragédias como Timothy McVeigh ao explodir o edifício Alfred Murrah, na Cidade de Oklahoma, em abril de 1995. Pelo contrário, enfoco a psicologia de grandes grupos que fere e mata pessoas em nome de sua identidade. Ao estudar a "realidade psíquica" do inimigo como um grande grupo, o grupo atacado pode explorar novas maneiras de lidar com ele e sua ameaça, ao invés de reagir ao inimigo e à ameaça por meio de sinais de sua própria regressão.

\section{Tornando-se igual ao inimigo}

A al-Qaeda dividiu o mundo em duas categorias. Depois do dia 11 de setembro, os Estados Unidos fizeram o mesmo (mais uma vez, não estou me referindo aqui a indivíduos, mas a um processo geral de grandes grupos), e idéias como a do "choque de civilizações" ou de religiões direta ou indiretamente receberam apoio da sociedade. Dividir o mundo em distintos "nós" e "eles" é um sinal da regressão de grandes grupos. Reagir ao inimigo de forma não regressiva constitui tarefa muito difícil. Medidas realistas e lógicas são facilmente contaminadas pelas emoções que confortam o desejo humano de infligir ao inimigo o que foi por ele infligido. Não creio que os seres humanos (como grandes grupos) já levaram em consideração a idéia ou desenvolveram a capacidade de se absterem de agir como os seus inimigos quando se sentem ameaçados ou feridos.

Preciso ter cautela para evitar mal-entendidos aqui. Não me refiro, por exemplo, ao que os nazistas e os aliados fizeram na Segunda Guerra Mundial, nem afirmo que os aliados eram como os nazistas. Muitos fatores, tais como as circunstâncias históricas, a reativação de vitimizações passadas, a constituição da personalidade do líder, o poder militar existente e, o mais importante de tudo, o grau de regressão dos grandes grupos, podem fazer com que um grande grupo desumanize o "outro" e aja com terrível crueldade. Ao lidar com um grande grupo assim, em estado de regressão extrema, o grupo oponente não precisa ficar em estado similar de tamanha regressão quanto o grupo perpetrador.

Quando falo de similaridade entre inimigos, refiro-me a determinados processos de grandes grupos sem levar em consideração o grau de sua regressão ou suas conseqüências. Em primeiro lugar, afirmo apenas que, ao ver sua identidade ameaçada, o grande grupo agredido automaticamente começa a ferir a identidade do grande grupo agressor; desse modo, o grupo atacado passa a mostrar similitudes com o atacante. Em segundo lugar, ambos os grupos utilizam mecanismos mentais comuns, tais como introjeção, projeção, negação, dissociação, isolamento, racionalização e intelectualização em sua propaganda política consciente ou inconscientemente motivada. Isso provém de sua liderança e/ou é desejada e apoiada pela sociedade. Em terceiro lugar, humilhar, ferir e matar pessoas em nome da identidade de grandes grupos tornase aceitável para ambos os lados.

Se a liderança não realizar algum tipo de teste da realidade que inclua a compreensão da "realidade psíquica" do inimigo (como grande grupo), nem fizer tentativas para reagir a isso de maneira humana, o perigo se amplia e a regressão se dá ou se mantém. Por conseguinte, a noção de o grande 
grupo igualar-se ao inimigo é uma área a ser estudada aberta e repetidamente até que novas oportunidades de reações diferentes (acima e além das militares) possam ser conceitualizadas. De fato, é possível considerar novas estratégias nas relações internacionais que não incluam sucumbir na regressão de grandes grupos, e é preciso que os chamados "canais diplomáticos" não estejam fechados até que se conclua uma avaliação psicopolítica da situação.

\section{Exame "microscópico" da influência negativa da psicologia de grandes grupos: a história de Klooga}

Há muitos outros conceitos relacionados à psicologia de grandes grupos que não estão tratados neste texto. Todavia, com as referências a luto e regressão de grandes grupos feitas acima, tentei ilustrar como a psicologia de grandes grupos em si mesma precisa ser estudada. Agora, narrando uma história da vila estoniana de Klooga, vou ilustrar, em nível microscópico, como as emoções e as percepções partilhadas de grandes grupos interferem nas questões políticas, militares, legais e de saúde, como nos tornamos semelhantes a nossos inimigos, e como precisamos dar atenção aos problemas psicológicos de grandes grupos, especialmente às suas questões de identidade, de sorte a encontrar soluções construtivas para nossos conflitos.

Depois que a Estônia alcançou a independência da União Soviética, em 1991, o país recémindependente enfrentou problemas graves, entre eles o fato de que um terço da população de um milhão e meio de habitantes não era composta de estonianos étnicos, mas de russos (ou falantes de russo que não eram russos étnicos, embora fossem ex-cidadãos russos). Em outras palavras, quando da independência da Estônia, um em cada três habitantes era visto como o "outro", o "inimigo". Quando o país se separou da União Soviética, seu povo se perguntou, "quem somos nós agora e, então, qual é a nossa identidade de grande grupo?" Essa preocupação com a identidade do grande grupo provocou uma regressão social exacerbada pela existência do grande número de "inimigos" na população estoniana, percebidos como capazes de contaminar a identidade do grande grupo.

Em 1994, fui à Estônia com uma equipe interdisciplinar para realizar um processo de diagnóstico e reunir indivíduos selecionados para participarem de diálogos psicopolíticos: estonianos de alto nível (como parlamentares, inclusive o atual presidente do país, Arnold Rüütel), representantes de alto nível de Moscou (como os membros da Duma Russa) e líderes dos russos (ou falantes de russo) habitantes da Estônia. Nós nos reunimos durante sete anos e, depois, começamos a aplicar na população em geral o que fora aprendido da série de diálogos ${ }^{16,19}$ Klooga foi o lugar escolhido para demonstrarmos a possibilidade de coexistência entre os estonianos étnicos e os russos que viviam no país.

Assim que cheguei a Klooga pela primeira vez, no início de 1996, a vila estava praticamente em ruínas e apresentava riscos graves de saúde pública; parecia um depósito de lixo de uns cinco quilômetros de comprimento por um e meio de largura. A municipalidade fica a apenas onze quilômetros de Paldiski, sede da antiga marinha nuclear soviética. À semelhança de Paldiski, Klooga abrigara uma instalação militar soviética, na qual era vedada a entrada de estonianos durante o regime russo; mas, depois da retirada dos militares soviéticos, alguns estonianos se radicaram na vila. Por ocasião de minha visita, sua população era de cerca de 2.000 habitantes, composta metade de estonianos e metade de russos (inclusive alguns falantes de russo).

O objetivo da equipe facilitadora em Klooga era desenvolver algum nível de coesão comunitária sem conflitos inter-étnicos. Com a ajuda de nosso trabalho psicopolítico, os residentes da vila criaram um centro comunitário que se tornou um local que todos podiam freqüentar para aprender (aulas de informática, inglês e estoniano) e brincar. As crianças tinham um lugar seguro para ir depois da escola. Os adolescentes se reuniam por lá também, e o centro sediava as comemorações de feriados para toda a comunidade. Juntamente com o sentido crescente de comunidade engendrado pelo centro, a saúde pública e outros aspectos da vida em Klooga também melhoraram.

É claro que houve obstáculos inevitáveis a nosso trabalho na vila. O exemplo narrado a seguir da experiência que tivemos lá, creio eu, ilustra em nível microscópico como as emoções e as percepções partilhadas por um grupo são capazes de instigar atos irrealistas, e como os membros do grupo podem ficar "cegos", impossibilitados de ver as conseqüências de tais atos.

Os recém-estabelecidos militares estonianos sem experiência, com alguns coronéis no comando, estavam usando um campo adjacente a Klooga para praticar alvo com munição viva, situação que dizia respeito aos habitantes da vila, tanto estonianos quanto russos, porque constituía perigo real para a população inteira, especialmente para as crianças. $\mathrm{O}$ que se passava internamente era mais ou menos o seguinte: Nós, estonianos, agora 
podemos nos identificar com nossos agressores. Em termos intelectuais, sabemos hoje que em Klooga vivem cidadãos estonianos e também crianças, mas em nossas mentes continuamos a encarar o local como base militar soviética. Por isso, repetidamente a bombardeamos. Os militares estonianos inexperientes podiam ter escolhido qualquer outro local no país para praticar alvo, mas insistiram em "bombardear" Klooga, a "vila russa", embora na realidade ela não mais o fosse.

O campo alvo da munição viva era separado da vila por uma estrada de terra de uns 4,5 a 6 metros de largura. A artilharia pesada quase diária no campo vizinho a Klooga era de fato perigosa, e nós receávamos que as crianças brincando nas cercanias pudessem ser feridas ou mortas. Houve o incidente de um morador estoniano da vila que foi atingido pela artilharia, ao tomar um atalho pelo campo com seu velho trator. Por incrível que pareça, o homem sobreviveu. No início, os coronéis avisavam aos moradores da vila quando as "bombas" iam ser lançadas; mas, depois, começaram a praticar alvo sem aviso prévio, o que naturalmente agravou a situação.

Assim, tivemos de elaborar um plano a fim de ilustrar o perigo existente para as autoridades estonianas. Em 4 de julho de 1997, minha equipe organizou uma grande festa comunitária em Klooga. Embora não fosse feita qualquer referência aos Estados Unidos e à sua independência, todos ficaram sabendo o significado da data (Dia da Independência dos EUA). Também convidamos diversos estonianos e falantes de russo que haviam participado da série original de diálogos psicopolíticos, inclusive alguns parlamentares, para comparecerem com os familiares. A maioria deles morava em Tallinn, a capital, e nós sabíamos que jamais haviam estado em Klooga antes. A embaixada russa enviou um diplomata de segundo escalão na carreira. O palco estava montado.

Depois da festa convidei-os para um passeio, levando os convivas em direção à estrada de terra que separava a vila do campo alvo de munição viva. Rezei para que o "bombardeio" fosse retomado, para que os convidados experimentassem o que era viver em Klooga. Sem se fazerem esperar, as explosões, "bum, bum", começaram. Era impossível ignorar a prática de alvo, que proporcionava a prova inequívoca do que os habitantes de Klooga vivenciavam todos os dias. No entanto, apesar de assistir aos perigos dessa prática por si próprios e até constatar que algumas crianças estonianas brincavam nas proximidades, nossos convidados do Parlamento não conseguiram tomar uma providência para a situação.

No dia seguinte, envidei esforços mais diretos para suspender o "bombardeio" de Klooga, mas ainda senti grande resistência por parte dos convidados. Com vagar, descobrimos maneiras de "educar" os residentes de Klooga sobre a psicologia da humilhação, o desejo de revidar, e os esforços muitas vezes estranhos e perigosos que as pessoas empregam para isso. Também discutimos o conceito de identificação com o agressor. Sem interferência nossa, os residentes da vila (100 deles) redigiram uma carta ao então presidente estoniano Lennart Meri pedindo a suspensão do tiroteio. Vivendo em Estados democráticos há muito estabelecidos, podemos pensar que essa seria a atitude natural e na realidade fácil de ser tomada. Vivendo, porém, sob o comunismo e assimilando regras e regulamentos daquele sistema político, ela significou para os moradores da vila um esforço drástico. Valeu a pena quando Klooga passou a receber a atenção nacional. Uma estação de televisão enviou seus repórteres e câmeras para a vila, provocando grande rebuliço sobre o "bombardeio" de Klooga. Os residentes da vila aprenderam a ser assertivos e a usar pressão política e da mídia e, conquanto o processo tenha levado três anos, eles conseguiram suspender o "bombardeio".

\section{Observações finais}

Este texto descreve a identidade de grandes grupos e como regridem ao ver ameaçada a sua identidade. A regressão de grandes grupos pode resultar em atos destrutivos que matam muitas pessoas e criam graves problemas de saúde pública. Os psicanalistas e outros profissionais de saúde mental que desejam estudar a psicologia de grandes grupos em si mesma e participar de esforços interdisciplinares têm muito a oferecer com vistas ao entendimento e à administração dos conflitos de grandes grupos. 


\section{Referências}

1. Freud S. Why war? Standard Edition, 1932-1964; 22:197- 215.

2. Arlow J. Motivations for peace. In: Winnik, R Moses, M Ostow. Psychological basis of war. Jerusalem: HZ/Jerusalem Academic Press, 1973. p. 193-204.

3. Volkan VD. The intertwining of the internal and external wars. Trabalho apresentado na conferência "Lost in Transmission". Stockbridge: MA: The Erikson Institute, the Austen Riggs Center; 2004. (October 16).

4. Blum H. Superego formation, adolescent transformation and the adult neurosis. J Amer Psychoanal Assoc 1985; 4:887-909.

5. Jokl AM. Zwei Fällezum Thema "Bewältigung der Vergangenheit." (Two cases referring to the theme of "mastering the past.") Frankfurt A.M.: Jüdischer Verlag, 1997.

6. Grubrich-Simitis I. Extremtraumatisierung als kumulatives Trauma: Psychoanalytische Studien über seelische Nachwirkungen der Konzentrationslagerhaft bei Überlebenden und ihren Kindern (Extreme traumatization as a cumulative trauma: Psychoanalytic studies on the mental effects of imprisonment in concentration camps on survivors and their children). Psyche 1979, 33:991-1023.

7. Ecstaedt, I. Nationalismus in der "zweiten Generation:" Psychoanalyse von Hörigkeitsverhältnissen (National Socialism in the Second Generation: Psychoanalysis of Master-Slave Relationships). Frankfurt AM: Suhrkamp Verlag, 1989.

8. Streeck-Fischer A. Naziskins in Germany: How traumatization deals with the past. Mind and Human Interaction 1999; 10: 84-97.

9. Volkan VD, G Ast, W Greer. The Third Reich in the unconscious: transgenerational transmission and its consequences. New York: Brunner-Routledge; 2002.

10. Freud S. Totem and taboo. Standard Edition, 1913-1955; 13:1-165.

11. Freud S. Group psychology and the analysis of the ego. Standard Edition 1921-1955; 18: 65-143.

12. Freud S. The future of an illusion. Standard Edition 19211959; 21: 5-56.

13. Freud, S. Civilization and its discontents. Standard Edition, 1930- 1959; 21: 59-145.

14. Hendrick I. Facts and theories of psychoanalysis. New York: Knopf; 1958.

15. Volkan VD. The need to have enemies and allies: from clinical practice to international relationships. Northvale, NJ: Jason Aronson; 1988.
16. Volkan VD. Bloodlines: from ethnic pride to ethnic terrorism. New York: Farrar- Straus and Giroux; 1997.

17. Volkan VD. Blind trust: large groups and their leaders in times of crises and terror. Charlottesville, VA: Pitchstone Publishing; 2004.

18. Volkan VD. Politics and international relations. In: ES Person, AM Cooper, GO Gabbard. Textbook of Psychoanalysis. Washington: American Psychiatric Press; 2005. p. 523-33.

19. Volkan VD. Killing in the name of identity: a study of bloody conflicts. Charlottesville, VA: Pitchstone Publishing; 2006.

20. Bion W. Experiences in groups and other papers. New York: Basic Books; 1961.

21. Rice AK. Learning for leadership: interpersonal and intergroup relations. London: Tavistock Publications; 1965.

22. Turquet $\mathrm{P}$. Threats to identity in the large group. In: L Kreeger. The large group: dynamics and therapy. London: Constable; 1975. p. 87-144.

23. Kernberg OF. Sanctioned political violence: A psychoanalytic view - Part1. Int J Psycho-Anal 2003; 84:683-98.

24. Kernberg OF. Sanctioned political violence: A psychoanalytic view - Part 2. Int J Psycho-Anal 2003; 84:683-98.

25. Volkan VD. Linking objects and linking phenomena: a study of the forms, symptoms, metapsychology, and therapy of complicated mourning. New York: International Universities Press; 1981

26. Pollock GH. The mourning-liberation process. vols 1 and 2. Madison, CT: International Universities Press; 1989.

27. Tähkä V. Dealing with object loss. Scandinavian Psychoanalytic Rev 1984, 7: 13-33.

28. Freud S. Mourning and melancholia. Standard Edition $1917-$ 1957, 14: 277-58.

29. Volkan VD, N Itzkowitz. Turks and Greeks: neighbors in conflict. Cambridgeshire; England: Eothen Press; 1994.

30. Waelder R. The principle of multiple function: Observations on over-determination. Psychoal Quart 1930-1936, 5:45-62.

31. Sebek M. The fate of the totalitarian object. Intel. Forum Psychoanal 1996, 5:289-294.

32. Rangell L. The mind of watergate. New York: Norton; 1980.

33. Stern J. Deviance in the Nazi society. Mind and human interaction 2001,12:218-37.

Artigo apresentado em 15/03/2006

Aprovado em 28/03/2006

Versão final apresentada em 28/03/2006 